DOI 10.37882/2223-2982.2021.03-2.22

\title{
ИНДИВИДУАЛЬНЫЙ ПОДХОД В РАМКАХ УЧЕБНЫХ ЗАНЯТИЙ ПО ФИЗИЧЕСКОЙ КУЛЬТУРЕ В СПЕЦИАЛЬНОЙ МЕДИЦИНСКОЙ ГРУППЕ
}

\section{INDIVIDUAL APPROACH \\ IN THE FRAMEWORK OF LEARNING LESSONS FOR PHYSICAL EDUCATION IN SPECIAL MEDICAL GROUP}

\section{Lavricheva \\ A. Ilyushin \\ V. Merkushev}

Summary: The article is devoted to the peculiarities of working with students in physical education classes in a special medical group. The purpose of the work is to draw up a generalized plan of work with students who have different diagnoses. The authors managed to compile recommended, restricted and prohibited types of exercises in a special group. The authors have compiled a set of exercises aimed at strengthening the spine and preventing scoliosis. The authors conclude that the individual approach to physical education classes in a special group is expressed in the nature of the exercises, their complex, duration and intensity.

Keywords: physical culture, a special medical group, an individual approach, a set of exercises.
Лавричева Ирина Анатольевна

К.п.н., Дочент, ФГБОУ ВО «Саратовская государственная юридическая академия»

irinalavricheva54@gmail.com

Илюшин Алексей Максимович

К.ф.н., Дочент, ФГБОУ ВО «Саратовская государственная юридическая академия»

fan-milan@mail.ru

Меркушев Владимир Григорьевич

Старший преподаватель, ФГБОУ ВО «Саратовская государственная юридическая академия» merkushevairaida@mail.ru

Аннотация: Статья посвящена особенностям работы с обучающимися на учебных занятиях по физической культуре в специальной медицинской группе. Целью работы является составление обобщенного плана работы со студентами, имеющими различные диагнозы. Авторам удалось составить рекомендуемые, ограниченные и запрещенные виды упражнений в специальной группе. Авторы составили комплекс упражнений, направленный на укрепление позвоночника и предотвращение сколиоза. Авторы приходят к выводу, что индивидуальный подход на занятиях физической культурой в специальной группе выражается в характере упражнений, их комплексе, длительности и интенсивности.

Ключевые слова: физическая культура, специальная медицинская группа, индивидуальный подход, комплекс упражнений.

Решение о направлении студента в специальную медицинскую группу принимает врач после длительного осмотра и постановки соответствующего диагноза. Необходимо отметить, что обучающиеся, которые отнесены по состоянию здоровья в специальную медицинскую группу, также нуждаются в двигательной активности. Однако им нужна активность качественно другого уровня.

В специальную подгруппу «A» зачисляются обучающиеся, имеющие значительные нарушения в состоянии здоровья постоянного или временного характера. Таким студентам необходимо ограничить физическую нагрузку. Занятия с обучающимися в специальной подгруппе «A» должны быть направлены на формирование общей выносливости [3].

Специальная подгруппа «Б» отличается тем, что в нее входят студенты, имеющие стойкие нарушения в состоянии здоровья, хронические заболевания разных стадий развития. Таким обучающимся необходимо выполнять регулярные самостоятельные задания в домашних условиях по индивидуальным комплексам $[1$, c. 6]. 
Отметим работы исследователей, посвященные изучению особенностей работы со студентами в рамках специальной медицинской группы. Коллектив преподавателей Российского экономического университета им. Г.В. Плеханова разработал методическую программу, в которой студенты основной, подготовительной и специальной группы занимаются одновременно. При этом преподаватель, ведущий занятие, должен учитывать особенности состояния здоровья студентов и возможные ограничения. В работе рассматриваются диагнозы, а также возможные варианты физической активности студентов в рамках учебного занятия [5, с. 109].

Исследователи Т.А. Путилина и В.В. Мноян, которые рассматривают особенности занятий со студентами в специальной группе на занятиях по физическому воспитанию, отмечают важность реабилитационных упражнений, в состав которых входят занятия легкой атлетикой, физическими упражнениями на улице, велоспортом и лыжным спортом. Особенностью проведения занятий является использование разнообразных дыхательных упражнений и игр на свежем воздухе [4, с. 67].

Целью данной работы является рассмотрение возможностей индивидуальной работы с обучающимися на занятиях по физическому воспитанию.

Научной новизной работы является разработка комплекса индивидуальных упражнений для обучающихся специальных учебных групп на занятиях физической культуры.

Практическая ченность данной статьи заключается в том, что эти рекомендации можно выполнять при подготовке к занятиям физической культуры, как в спортивном зале, так и на свежем воздухе.

С целью составления индивидуального комплекса упражнений для студентов необходимо учитывать их физическое состояние и поставленный доктором диагноз.

Каждое занятие по физическому воспитанию в специальной медицинской группе может включать в себя пять основных этапов:

1. Вводная часть. На этом этапе проводится оценка физического состояния обучающихся, определение их готовности к выполнению упражнений.

2. Подготовительная часть - разминка. Здесь необходимо подготовить организм к выполнению упражнений. На этом этапе необходимо включить ходьбу в среднем темпе с упражнениями на мышцы бедра, голени, стоп. Кроме этого, необходимо подключить движения для активизации мышц верхних конечностей, плечевого пояса, шейного отдела позвоночника. В этот блок можно включить упражнения на координацию и дыхательную гимнастику.

3. Основная часть. На этом этапе проводятся упражнения, которые развивают двигательные навыки и физические качества студентов. Упражнения для спины рекомендуется выполнять всем обучающимся, поскольку длительное неподвижное сидение способствует формированию нарушенного ортопедического режима.

4. Вариативная часть, которая проводится по индивидуальному плану, разработанному для каждого студента с учетом его физических возможностей и особенностей развития.

5. Заключительная часть, на которой темп упражнений замедляется. Здесь возможны упражнения на растягивание и дыхательная гимнастика.

Особенности реализации вариативной части на занятиях физической культурой в специальной медицинской группе рассмотрим в табл. 1.

Нам удалось составить рекомендации по типу выполняемых упражнений на занятиях по физической культуре в специальной группе. Составим комплекс упражнений, направленный на улучшение кровоснабжения в суставах при сколиозе, плоскостопии, полой стопе и др. заболеваниях опорно-двигательного аппарата и суставов:

1. Поднимание и опускание пяток и носков.

2. Поднять правую ногу - вдох, вернуться в исходное положение. Поднять левую ногу - вдох - исходное положение.

3. Круговое движение левой и правой ногой по очереди.

4. Наклоны в стороны, скользя кистями по бедрам.

5. Махи руками (4-6 раз).

6. Рывки руками.

7. Наклоны вправо и влево. Медленный темп.

8. Круговые вращения руками по часовой стрелке и против часовой стрелки.

9. Вращение головой вправо и влево.

10. Упражнения с гимнастической палкой (поднимание, наклоны).

Большую часть упражнений необходимо проводить на полу лежа, в упоре стоя на коленях или сидя. Обычно каждое упражнение рекомендуется повторять 4-6 раз. Однако продолжительность занятий и интенсивность зависит от возраста, пола, характера нарушения осанки, прогрессивности заболевания.

Таким образом, нам удалось составить перечень общих рекомендаций при работе с обучающимися, у которых диагностированы различные виды заболеваний. Данные рекомендации подойдут детям школьного возраста и студентам высших и средних учебных заведений.

Мы составили примерный комплекс упражнений, ко- 
Таблица. 1.

Индивидуальные рекомендации при проведении занятий с обучающимися в специальной медицинской группе

\section{Характеристика заболеваний}

Заболевания сердечнососудистой системы (гипертоническая болезнь, артериальная гипотензия, приобретенные пороки сердца, др.)

\begin{tabular}{l} 
\\
\hline $\begin{array}{l}\text { Заболевания органов } \\
\text { дыхания (бронхиаль- } \\
\text { ная астма, хронический } \\
\text { бронхит) }\end{array}$
\end{tabular}

\section{Задачи для данной группь}

1.Улучшить периферическое кровоснабжение.

2.Устранить нервно-мышечное напряжение.

3.Улучшить психоэмоциональное состояние.

4.Повысить толерантность К физическим упражнениям.

5. Повысить тонус организма в целом.

\section{вка выдоха. \\ 2. Установить более редкое ды-} хание с большим потреблением кислорода.

3. Снять спазмы бронхов и бронхиол, нормализировать акты дыхания.

4. Укрепление мышц, принимающих участие в актах дыхания. 5. Увеличить потребность диафрагмы и грудной клетки. Нормализовать тонус центральной нервной системы.
Заболевания органов пищеварения, органов мочевыделения и 06мена веществ (гастрит, язвенная болезнь, дискинезия желчевыводящих путей, пиелонефрит, др.)

1. Укрепить мышцы брюшного пояса.

2. Активировать кровообращение в брюшной полости и малом тазу.

3. Активизировать перистальтику желчного пузыря.

4. Нормализировать моторику и секреции желудка.

5. Повысить общий тонус и улучшить психоэмоциональное состояние.

6. Повысить физическую работоспособность.

\section{Заболевания опор-} но-двигательного аппарата и суставов. Последствия различных травм (сколиоз, плоскостопие, артрит, др.)
1. Улучшить кровообращение в суставах.

2. Укрепить мышечную систему. 3. Способствовать формированию рационального мышечного корсета.

4. Укрепить голени и стопы.

Рекоменоуемые
упражнения

1. Ходьба от 4 до 8 км.

2. Бег в медленном темпе.

3. Прогулка на лыжах.

4. Плавание.

5. Упражнения на мелкие и средние группы мышц.

6. Спуски и подъемы.

7. Полное расслабление отдельных групп мышц и максимальное напряжение при пассивном положении тела.

1. 0бщеразвивающие упражнения для плечевого пояса.

2. Упражнения с медленным полноценным и удлиненным выдохом.

3. Упражнения с отягощениями и предметами.

4. Упражнения на расслабление

5. Ходьба.

6. Медленный бег.

7. Прогулки на лыжах.

8. Плавание.

1. 0бщеразвивающие упражнения через 3-3,5 часа после приема пищи.

2. Упражнения для укрепления мышц брюшного пресса.

3. Дыхательные упражнения.

4. Бег трусцой.

5. Плавание, гребля.

6. Прогулки на лыжах.

7. Катание на велосипеде.

8. Подвижные игры.

9. Упражнения в расслаблении

мышц поясничной области.

\section{1. Плавание.}

2. Гребля.

3. Прогулки на лыжах.

4. Корригирующие упражнения. 5. Упражнения на расслабление и координацию.

6. Общеразвивающие упражнения, направленные на укрепление позвоночника.

7. Дыхательные упражнения. 8. Ходьба на носках, на пятках, на внутреннем и наружном своде стопы.
Упражнения, которые необходимо ограничить

\begin{tabular}{l|l} 
1.Упражнения, при которых & 1. Нагрузки силового и
\end{tabular} голова ниже горизонтального уровня.

2. Упражнения силового характера.

3. Упражнения, которые выполняются на скорость.

1.Небольшая продолжительность занятий.

2. Бег при низких температурах воздуха.

\section{1. Участие в эстафетах и} спортивных играх.

2. Упражнения, вызывающие сотрясение внутренних органов.

3. Упражнения с отягощениями.

4. Упражнения на статическое напряжение мышц.

5. Выполнение подскоков в подвижных играх.

1. Осевая нагрузка на позвоночник.

2. Пассивные упражнения для больных суставов.

3. Прыжки.
Противопоказано задержкой дыхания.

2. Упражнения, вызывающие одышку, сердцебиение, перебои в работе сердца (движения с большой амплитудой).

1. Силовые упражнения с задержкой дыхания.

2. Упражнения на гипервентиляцию легких (глубокий вдох и выход).

3. Резкие движения, сбивающие ритм дыхания.

1. Интенсивные и длительные нагрузки.

2. Выполнение упражнений при болях в брюшной полости.

3. Упражнения силового характера, направленные на укрепление мышц пресса. 4. Интенсивные статистические нагрузки.

1. Упражнения, которые фиксируют искривленный позвоночник.

2. Упражнения, которые сопровождаются болезненностью.

3. Прыжки в длину и в высоту.

4. Поднятие тяжестей.

5. Неравномерные нагрузки на позвоночник.

6. Наклоны, скручивания, повороты. 


\begin{tabular}{|c|c|c|c|c|}
\hline $\begin{array}{l}\text { Характеристика } \\
\text { заболеваний }\end{array}$ & Задачи для данной группы & $\begin{array}{c}\text { Рекомендуемые } \\
\text { упражнения }\end{array}$ & $\begin{array}{l}\text { Упражнения, которые } \\
\text { необходимо ограничить }\end{array}$ & Противопоказано \\
\hline $\begin{array}{l}\text { Заболевания нервной } \\
\text { системы (вегетососуди- } \\
\text { стая дистания) }\end{array}$ & $\begin{array}{l}\text { 1. Устранить патологический } \\
\text { мышечный тонус. } \\
\text { 2. Корректировать осанку. } \\
\text { 3. Восстановить подвижность } \\
\text { больных отделов позвоночника. } \\
\text { 4. Укрепить мышцы туловища } \\
\text { и шеи. } \\
\text { 5. Нормализовать реакцию } \\
\text { вегетативной нервной системы } \\
\text { на внешние раздражители }\end{array}$ & $\begin{array}{l}\text { 1. Упражнения для формирова- } \\
\text { ния правильной осанки. } \\
\text { 2. Формирование мышечного } \\
\text { корсета. } \\
\text { 3. Висы на турнике. } \\
\text { 4. Плавание и упражнения в } \\
\text { воде. } \\
\text { 5. Упражнения для мышц шеи } \\
\text { на сопротивление. }\end{array}$ & $\begin{array}{l}\text { 1. Осевая нагрузка на по- } \\
\text { звоночник. } \\
\text { 2. Упражнения, способные } \\
\text { спровоцировать заболева- } \\
\text { ния позвоночника. } \\
\text { 3. Прыжки. } \\
\text { 4. Упражнения с отягоще- } \\
\text { ниями. } \\
\text { 5. Активные движения } \\
\text { головой. }\end{array}$ & $\begin{array}{l}\text { 1. Подъем и перемещение } \\
\text { тяжелых предметов. } \\
\text { 2. Повороты на 150-450 без } \\
\text { дополнительной нагрузки и } \\
\text { наклоны туловища. } \\
\text { 3. Резкие старты и оста- } \\
\text { новки. } \\
\text { 4. Спортивные игры. } \\
\text { 5. Физические упражнения } \\
\text { при болях в суставах. } \\
\text { 6. Резкие подскоки и на- } \\
\text { клоны. }\end{array}$ \\
\hline $\begin{array}{l}\text { Нарушение зрения } \\
\text { (миопия) }\end{array}$ & $\begin{array}{l}\text { 1. Улучшить кровоснабжение в } \\
\text { тканях глаза. } \\
\text { 2. Улучшить деятельность } \\
\text { мышц глаза. } \\
\text { 3. Общее укрепление организ- } \\
\text { ма. }\end{array}$ & $\begin{array}{l}\text { 1. Бег в медленном темпе. } \\
\text { 2. Прогулки на лыжах. } \\
\text { 3. Плавание. } \\
\text { 4. Велосипед. } \\
\text { 5. Упражнения на растягивание. } \\
\text { 6. Дыхательные упражнения. }\end{array}$ & $\begin{array}{l}\text { 1. Большая нагрузка на } \\
\text { зрительный анализатор. } \\
\text { 2. Упражнения головой } \\
\text { вниз. }\end{array}$ & $\begin{array}{l}\text { 1. Поднятие тяжестей. } \\
\text { 2. Прыжки. } \\
\text { 3. Упражнения силового } \\
\text { характера с задержкой } \\
\text { дыхания. } \\
\text { 4. Упражнения с на- } \\
\text { пряжением зрительного } \\
\text { анализатора. } \\
\text { 5. Резкие перемещения } \\
\text { тела. }\end{array}$ \\
\hline
\end{tabular}

Источник: [1, с. 9-14], составлено и объединено автором.

торый можно включить в вариативную часть занятия со студентами, имеющими заболевания опорно-двигательного аппарата. Из-за длительного нахождения в положении сидя во время учебных занятий у многих обучающихся развиваются сколиозы, кифозы и лордозы разной степени. Это можно предотвратить и избежать ухудшения самочувствия, если дополнительно к учебным занятиям по физической культуре добавить выполнение индивидуальных комплексов на факультативных занятиях в спортивном зале или на свежем воздухе.
Индивидуальный подход выражается в характере упражнений, их подборе, длительности и интенсивности. Эти показатели зависят от возможностей обучающихся. Индивидуальные программы направлены на улучшение эффективности проводимых занятий в специальной медицинской группе, увеличивая эффективность занятий физической культурой. При этом у студентов повышается интерес к занятию спортом, к соблюдению здорового образа жизни и готовность к освоению профессиональной деятельности.

\section{ЛИТЕРАТУРА}

1. Методические рекомендации к проведению занятий физической культурой со студентами специальной медицинской группы / 0.С. Рогов, В.Ф. Кошелев, Ю.Г. Бердникова, Т.Н. Смолина. - Екатеринбург: Редакционно-издательский отдел Углту, 2014. - 31 с.

2. Особенности реализации образовательных программ в области физической культуры и спорта // Закон об образовании от 29.12.2012 № 273-Ф3 (Ред. 0т 17.02.2021) - Статья 84 [Электронный ресурс]. - URL: http://www.consultant.ru/document/cons_doc_LAW_140174/89677d6cc3961e4197637f3aa2f32cd2d е7261еа/ Дата обращения: 18.03.2021.

3. Правила определения медицинских групп для занятий несовершеннолетними физической культурой. Приложение 3 // Порядок проведения медицинских осмотров несовершеннолетних от 10.08.2017 № 514н [Электронный ресурс]. - URL: https://base.garant.ru/71748018/5da741911cf9399494368b18de8 Ofbe8/ Дата обращения: 19.03.2021.

4. Путилина Т.А., Мноян В.В. Цели и задачи занятий физической культурой в специальной медицинской группе // Творческий научный обозреватель Октябрь, 2017. - № 10 (27). - С. 66-71.

5. Шепель С.П., Макаренкова Т.И., Внукова Е.Ю. Михальченко Е.Г. Особенности занятий со студентами специальной медицинской группы в рамках учебных заведений // Известия Тульского государственного университета. Физическая культура. Спорт. - 2018. - № 3. - С. 107-114.

(с) Лавричева Ирина Анатольевна (irinalavricheva54@gmail.com), Илюшин Алексей Максимович (fan-milan@mail.ru), Меркушев Владимир Григорьевич (merkushevairaida@mail.ru).

Журнал «Современная наука: актуальные проблемы теории и практики» 